\title{
Bio-flocculent $v$ s. inorganic flocculent in the removal of pesticides from water - A comparative study
}

\author{
Om Pal Singh ${ }^{1,2 *}$, Aditya Kapil Valiveti ${ }^{1}$, Anuradha Mishra ${ }^{2}$, L.K. Thakur ${ }^{1}$ and S. K. Raza ${ }^{1}$ \\ ${ }^{1}$ Analytical Division, Institute of Pesticide Formulation Technology, Sector- 20, Udyog Vihar, \\ Gurgaon, Haryana- 122016 \\ ${ }^{2}$ SoVSAS, Gautam Buddha University, Greater Noida, Gautam Buddha Nagar, Utter Pradesh- \\ 201308, \\ *Email: ompals.jayant@gmail.com
}

Contamination of water sources is a major problem in the developing countries around the world. Day by day demand for food being increased with increasing population. As a result, usage of pesticides is a common practice in many countries to control the diseases causing by pests and thereby increase in the productivity and storage capacity of the agriculture products. On the other hand, the extensive usage of these chemical agents in the agricultural practices leading to the pollution of the major environmental bodies such as water, soil and air. Atrazine is herbicide of triazine group. It is widely used as pre and post emergent herbicide to control broadleaf weeds. Atrazine is found frequently in the water sources from several places and it is very toxic and carcinogenic in nature.

Therefore, study regarding decontamination of water sources from pesticides and their metabolites are most essential task for today's researcher. Various types of adsorbents have been used for pesticides removal from water. Nanomaterials and bio-flocculants both are recently developed techniques and playing a vital role for pesticides removal from water.

In present study, authors focused to develop and compare the efficiencies of adsorptive removal of Atrazine from water with two individual bio-flocculent (polysaccharide) and nanomaterial (INPs).

Natural biopolymers and composite iron nanoparticles were synthesized, analyzed and applied for atrazine removal from water. For this, bio-flocculants were extracted from okra fruit (Abelmoschus esculentus) by using a water extraction method. Iron nano-composite is used as inorganic flocculent in order to observe their efficacy in the removal of pesticide from water. Green technology was used to synthesize iron nanoparticles (INPs) by adopting a method from literature with slight modification. Both the materials were characterized by particle size analyzer, TEM, XRD and SEM methods. Extraction of residual pesticide from water was done with dichloromethane (DCM). Gas chromatography (GC) was used as analytical techniques for residue analysis of pesticides.

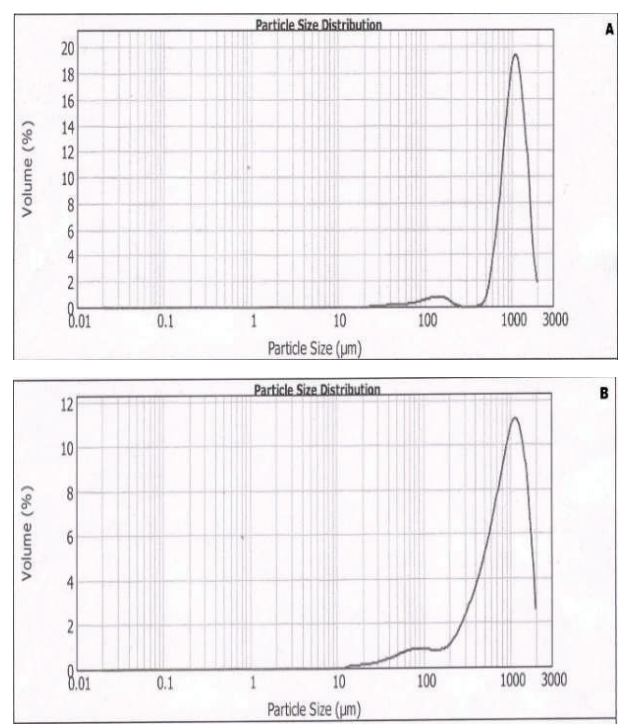

Figure 1: Ranges of particle size of polymer (A) without grinded and (B) grinded

\section{References}

1. M. T. Amin, A. A. Alazba, U. Manzoor. Advances in Material Science and Engineering, Vol. 2014 (2014) pp. 1-24.

2. C. S. Lee, M. F. Chong, J. Robinson, E. Binner. Industrial \& Engineering Chemistry Research, Vol. 53 (2014) pp.18357-18369.

3. C. S. Lee, M. F. Chong, J. Robinson, E. Binner. Journal of Environmental Management. Vol. 157 (2015) pp.320-325. 